\title{
Ten reasons for focusing on the care we provide for family members of critically ill patients with COVID-19
}

\author{
Élie Azoulay ${ }^{2 *} \mathbb{D}$, J. Randall Curtis ${ }^{1}$ and Nancy Kentish-Barnes ${ }^{2}$
}

๑ 2020 Springer-Verlag GmbH Germany, part of Springer Nature

The novel coronavirus has become a worldwide threat and healthcare crisis. Since its outbreak in China at the end of 2019, the pandemic has affected millions of people and caused several hundred thousand deaths globally [1]. Approximately $20 \%$ of hospitalized patients with coronavirus disease 2019 (COVID-19) are admitted to the intensive care unit (ICU) for hypoxemic respiratory failure, and 60 to $90 \%$ receive mechanical ventilation [2]. Human to human transmission of SARS-CoV-2 occurs mostly through respiratory droplets and through direct contact with an infected patient [3], highlighting the importance of stay-at-home orders [4]. Stay-at-home orders, in addition to social distancing guidelines, general pandemic awareness, and restriction of hospital visits, has demonstrated effectiveness not only to reduce the number of people infected by each infected person, but also cumulative hospitalizations [4]. This short article discusses the multiple elements that contribute to the difficulty of caring for family members of critically ill patients with COVID-19 in this context, drawing on evidence before and during the COVID-19 pandemic [5-8].

\section{Acute respiratory failure and ARDS increase the risk of psychological distress for family members suggesting the COVID-19 pandemic will increase family psychological distress}

Survivors of acute respiratory distress syndrome (ARDS) and their family members endorse the importance of the domains of the post-ICU syndrome, which includes

\footnotetext{
*Correspondence: elie.azoulay@aphp.fr

${ }^{2}$ Médecine Intensive et Réanimation, Groupe FAMIREA, Hôpital Saint-Louis, Université de Paris, Paris, France

Full author information is available at the end of the article
}

cognitive impairment and psychological symptoms such as symptoms of depression and post-traumatic stress disorder (PTSD) [9]. These symptoms are prevalent among ARDS survivors, but these patients' family members can exhibit even higher prevalence of psychological symptoms and slower improvement over time than patients $[9,10]$. One year after prolonged mechanical ventilation, $61 \%$ of relatives still care for a spouse and about half of relatives report depressive symptoms [11]. Worse mental health outcomes have been reported in younger relatives and those with less social support [11]. Therefore, these findings suggest that many family members of patients with COVID-19 are at high risk of psychological distress and may need additional support.

\section{Patients' physical and psychological symptoms are an important determinant of family member psychological symptoms}

Family members' perception of the patient's dying and death can affect their psychological well-being for months and years after [12]. For example, perceptions by the relative that the patient could not breathe peacefully are associated with higher risk of PTSD symptoms 6 months after the patient's death in the ICU [12]. If family members are unable to be with patients and unable to evaluate their comfort, they may imagine that patient comfort is worse than it actually is. We know that doubt and uncertainty about the patient's circumstances at the end-of-life can generate guilt, anxiety, and post-traumatic stress [13]. In the context of COVID-19, when family members are often unable to see their loved-one in the ICU, clear and repeated communication about patient comfort is important to reassure family members and hopefully reduce the risk of developing anxiety and

\section{Springer}


PTSD. Video technology may also allow family members to see their loved one's comfort level for themselves.

\section{PTSD and complicated grief among family members are likely to be increased during the COVID-19 pandemic}

Relatives of patients who die in the ICU are at high risk for PTSD [13] and complicated grief [12], as well as dissatisfaction with communication, inability to say goodbye to their loved one, and a perceived lack of empathy from healthcare providers; these complications are increased when family visits are limited [14]. Hence, family members during the pandemic are particularly vulnerable. Instead of depriving the relatives of effective communication during such a stressful time, novel strategies to improve communication must be developed and implemented.

\section{Lockdown reduces resilience and increases anxiety for family members and clinicians}

Lockdown generates frustration, anxiety, and PTSD in the general population, and also limits social support further exacerbating these symptoms [7]. Psychological distress is also worsened by the feeling of loneliness [15]. As family visits are reduced or suspended, and as healthcare providers are also experiencing stress symptoms [16], providers are less able to provide empathy and meet family members' needs for emotional support. Family members are therefore simultaneously receiving less support both from their own social networks and from the ICU team.

\section{Personal protective equipment may produce a sense of depersonalization in clinician-family relationships}

ICU clinicians are obliged to wear personal protective equipment (PPE), including gloves, masks and gowns, due to the possibility of contamination [17]. Studies have shown the detrimental effects of isolation on patients (depression, anxiety and anger), and demonstrate that healthcare workers spent less time with patients in isolation [18]. Whether PPE actually increases psychological distress in relatives has not been yet established, but seems likely. Clinicians should be aware of this risk and talk with patients and family members about it (Fig. 1).

\section{Family visiting policies have been suspended or limited in most ICUs}

To ensure patient, staff and visitor safety, visiting policies have been suspended in many hospitals during the COVID-19 outbreak. Limitations may be particularly difficult in ICUs, where family visits have been greatly liberalized over the last two decades with strong support from family members and ICU clinicians [19]. The inability to maintain this link with relatives is a major source of stress for ICU clinicians $[5,6]$. Routine phone calls made by psychologists, palliative care providers, or other allied professionals can provide additional support for relatives and add value to the phone calls between family and ICU doctors or nurses. Moreover, videoconferences and the use of advanced technologies to support communication between conscious patients and relatives, as well as family conferences between ICU clinicians and family members, may limit the psychological burden of limited visits.
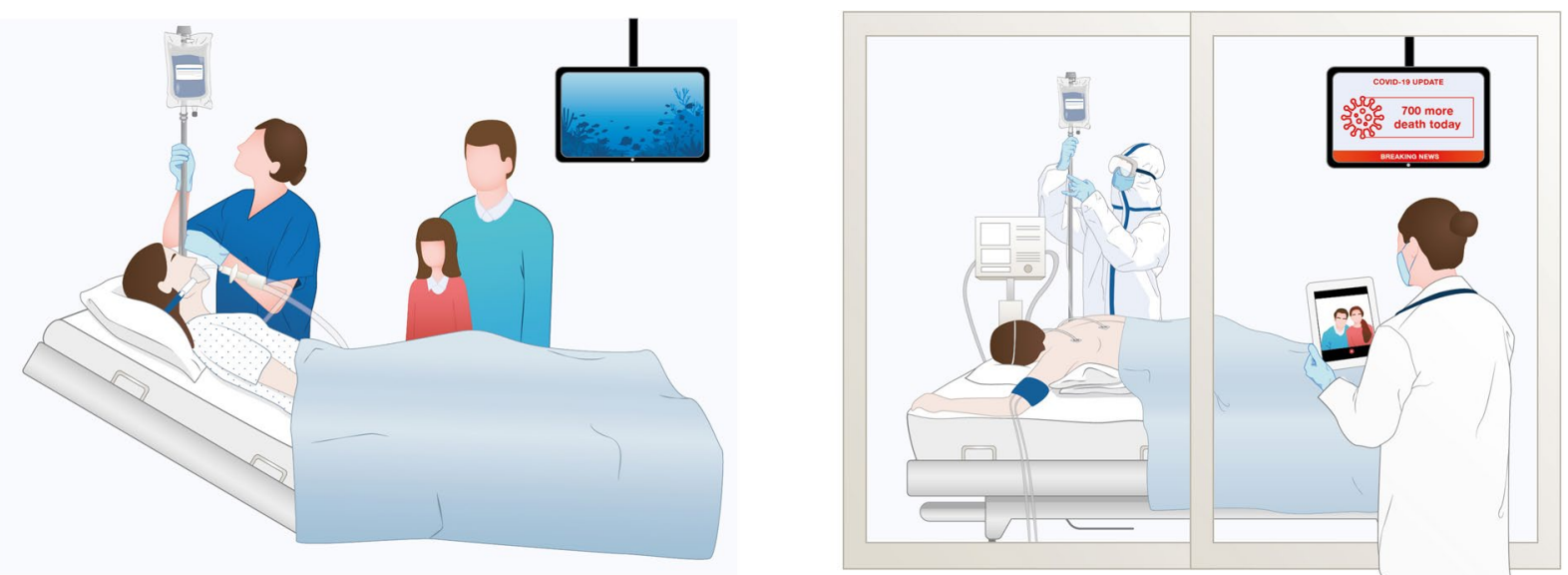

Fig. 1 Family visit policies at the era of COVID-19. Left side, before the SARS-CoV-2 pandemic: Family presence at the bedside during a nursing care. Family visiting policies are liberal and there is no isolation. The relatives can receive daily information either in the room or in a place dedicated to family information. Right side, during the SARS-CoV-2 pandemic: visiting policies have been suspended and the bedside nurse wears protective personal equipment making her/him unrecognizable. The patient is undergoing prone positioning as a rescue strategy for severe hypoxemia and her/his face is imperceptible. Last, a resident is having a videoconference with the relatives 
When patients are in the end-of-life situations, many hospitals have been able to modify limitations, allowing family members to see their loved ones and say good-bye. When family members wish to have this opportunity, it is important to offer it.

\section{Hospitals may be reluctant to share scarce PPE with relatives which may eliminate family visits at the end of life}

The COVID-19 pandemic has dramatically increased the need for PPE, causing shortages and posing tremendous challenges to many healthcare systems. Strategies for optimizing the supply of facemasks and other PPE may include suspension of family visits even in end-of-life situations, reserving PPE for healthcare providers. This limitation may be unavoidable, but should be reversed as soon as possible.

\section{Even when allowed to visit the ICU to see a dying relative, family members may not be able to do so}

In some ICUs, family visits are possible even though restricted. However, some relatives may not come to the hospital for psychological, practical (difficult access to public transport), or health-related reasons (such as having COVID-19 themselves). The pandemic has caused a variety of emotions for many, including fear of exposure to SARS-CoV-2 infection in the hospital and public spaces, fears often enhanced by frustration, sadness, anxiety, and stress [7]. Moreover, for family members who are unable to come to the hospital, this social isolation can increase time and opportunity for imagination and doubt: imagining the patient in the ICU can sometimes be worse than actually seeing the patient [20]. Not being at the patient's bedside and not being included in patient care may also generate feelings of guilt as families may blame themselves for not having tried harder to see their loved one while in the ICU and for not taking care of their relative's comfort and dignity during the hospital stay. Additional support for family members in this context is particularly important.

\section{9. "Infodemic" adds to family members' burden}

During the epidemic, people may feel overwhelmed by information overload, coming from traditional media (radio, television, newspapers) as well as digital media (received on smartphones). Constantly watching updates on the COVID-19 pandemic may increase anxiety. Moreover, the information received is not always correct. As a consequence, not only are we living in a pandemic, but also in an "infodemic" where inaccurate and sensationalized news is becoming increasingly common (https ://www.theguardian.com/world/2020/mar/03/battlingcoronavirus-misinformation-in-the-age-of-social-media
). People may feel overwhelmed and fatigued from the over-abundance of information, not knowing what to believe. Access to information from reliable sources, such as government healthcare authorities, should be prioritized and could be used to help ICU family members better understand the situation.

\section{Stressed clinicians are less able to provide support to family members}

COVID-19 has generated tremendous psychological burden on healthcare workers [16]. Clinicians often fear becoming sick or contaminating their colleagues or family. Moreover, facing increased number of end-oflife situations, especially with limited interaction with the relatives, can expose clinicians to moral distress and burnout. Hence, stressed and overworked clinicians may have difficulties providing optimal support to family members.

In conclusion, family members of critically ill patients with COVID-19 are exposed to high levels of psychological stress. Family members may have seen patients breathing laboriously prior to the hospital and are often managing increased uncertainty about their loved one's health and healthcare in the context of already being physically and emotionally exhausted by the pandemic and lockdown. In a setting where many hospitals have reduced or suspended family visits, where clinicians themselves are psychologically affected-fearful of being contaminated and forced to wear dehumanizing protective equipment-targeted and innovative communication strategies must be developed. We must find novel ways to maintain the connection between patients, family members, and healthcare providers. These novel strategies should preserve the quantity and the quality of the information provided to the relatives and address their needs for information and support. When ICU visits do not hamper family members' safety, clinicians should tailor family visits to each individual patient's situation. Whatever communication modality, from mostly remote communication (telephone, text messages, what's app groups, e-communication, videoconferences) to more conventional communication with in-person visits, our goal should be to empower family members to care for the patient, support them during their distress, prepare them to share in decision-making, and, in end-of-life situations, allow them to say goodbye to the patient.

\footnotetext{
Author details

${ }^{1}$ Critical Care Department of the St-Louis Hospital and the FAMIREA Study Group (EA, NKB), Paris, France. ${ }^{2}$ Médecine Intensive et Réanimation, Groupe FAMIREA, Hôpital Saint-Louis, Université de Paris, Paris, France.
} 


\section{Compliance with ethical standards}

\section{Conflicts of interest}

Authors declare no conflict of interest in relation with this manuscript.

\section{Publisher's Note}

Springer Nature remains neutral with regard to jurisdictional claims in published maps and institutional affiliations.

Received: 17 July 2020 Accepted: 3 November 2020

Published online: 24 November 2020

\section{References}

1. Aziz S, Arabi YM, Alhazzani W et al (2020) Managing ICU surge during the COVID-19 crisis: rapid guidelines. Intensive Care Med. https://doi. org/10.1007/s00134-020-06092-5

2. Feng Y, Ling Y, Bai T et al (2020) COVID-19 with different severity: a multicenter study of clinical features. Am J Respir Crit Care Med. https://doi. org/10.1164/rccm.202002-0445OC

3. Wiersinga WJ, Rhodes A, Cheng AC et al (2020) Pathophysiology, transmission, diagnosis, and treatment of coronavirus disease 2019 (COVID19): a review. JAMA. https://doi.org/10.1001/jama.2020.12839

4. Sen S, Karaca-Mandic P, Georgiou A (2020) Association of stay-at-home orders with COVID-19 hospitalizations in 4 states. JAMA 323:2522-2524. https://doi.org/10.1001/jama.2020.9176

5. Hart JL, Turnbull AE, Oppenheim IM, Courtright KR (2020) Family-Centered care during the COVID-19 era. J Pain Symptom Manage. https://doi. org/10.1016/j.jpainsymman.2020.04.017

6. Azoulay E, Kentish-Barnes N (2020) A 5-point strategy for improved connection with relatives of critically ill patients with COVID-19. Lancet Respir Med 8:e52. https://doi.org/10.1016/S2213-2600(20)30223-X

7. Brooks SK, Webster RK, Smith LE et al (2020) The psychological impact of quarantine and how to reduce it: rapid review of the evidence. Lancet Lond Engl 395:912-920. https://doi.org/10.1016/S0140-6736(20)30460-8

8. Montauk TR, Kuhl EA (2020) COVID-related family separation and trauma in the intensive care unit. Psychol Trauma Theory Res Pract Policy. https:// doi.org/10.1037/tra0000839
9. Dinglas VD, Chessare CM, Davis WE et al (2018) Perspectives of survivors, families and researchers on key outcomes for research in acute respiratory failure. Thorax 73:7-12. https://doi.org/10.1136/thoraxjnl-2017-21023 4

10. Herridge MS, Moss M, Hough CL et al (2016) Recovery and outcomes after the acute respiratory distress syndrome (ARDS) in patients and their family caregivers. Intensive Care Med 42:725-738. https://doi. org/10.1007/s00134-016-4321-8

11. Cameron Jl, Chu LM, Matte A et al (2016) One-year outcomes in caregivers of critically III patients. N Engl J Med 374:1831-1841. https://doi. org/10.1056/NEJMoa1511160

12. Kentish-Barnes N, Chaize M, Seegers V et al (2015) Complicated grief after death of a relative in the intensive care unit. Eur Respir J 45:1341-1352. https://doi.org/10.1183/09031936.00160014

13. Azoulay E, Pochard F, Kentish-Barnes $\mathrm{N}$ et al (2005) Risk of post-traumatic stress symptoms in family members of intensive care unit patients. Am J Respir Crit Care Med 171:987-994. https://doi.org/10.1164/rccm.20040 9-12950C

14. Kentish-Barnes N, Seegers V, Legriel S et al (2016) CAESAR: a new tool to assess relatives' experience of dying and death in the ICU. Intensive Care Med 42:995-1002. https://doi.org/10.1007/s00134-016-4260-4

15. McGinty EE, Presskreischer R, Han H, Barry CL (2020) Psychological distress and loneliness reported by US adults in 2018 and April 2020. JAMA 324:93-94. https://doi.org/10.1001/jama.2020.9740

16. Lai J, Ma S, Wang Y et al (2020) Factors associated with mental health outcomes among health care workers exposed to coronavirus disease 2019. JAMA Netw Open 3:e203976. https://doi.org/10.1001/jamanetwor kopen.2020.3976

17. Kleinpell R, Ferraro DM, Maves RC et al (2020) Coronavirus disease 2019 pandemic measures: reports from a national survey of 9,120 ICU clinicians. Crit Care Med. https://doi.org/10.1097/CCM.0000000000004521

18. Abad C, Fearday A, Safdar N (2010) Adverse effects of isolation in hospitalised patients: a systematic review. J Hosp Infect 76:97-102. https://doi. org/10.1016/j.jhin.2010.04.027

19. Davidson JE, Aslakson RA, Long AC et al (2017) Guidelines for familycentered care in the neonatal, pediatric, and adult ICU. Crit Care Med 45:103-128. https://doi.org/10.1097/CCM.0000000000002169

20. Wangmo T, De Clerca E, Ruhe KM et al (2017) Better to know than to imagine: Including children in their health care. AJOB Empir Bioeth 8:11-20. https://doi.org/10.1080/23294515.2016.1207724 